\title{
Methods for managing erectile function in cis- and trans-male patients after neophallus reconstruction
}

\author{
Christopher R. Koller ${ }^{1}$, Ayman Soubra ${ }^{2}$, Jacob Tannenbaum ${ }^{1,2}$, Laith Alzweri ${ }^{3}$, Wayne Hellstrom ${ }^{2}$ \\ 'Urology, Tulane University Medical Center, New Orleans, LA 70112, USA. \\ ${ }^{2}$ Department of Urology, Tulane University School of Medicine, New Orleans, LA 70112, USA. \\ ${ }^{3}$ Urology, UTMB Health, Galveston, TX 77555, USA.
}

Correspondence to: Dr. Wayne Hellstrom, Department of Urology, Tulane University Medical Center, 1430 Tulane Ave, 86-42, New Orleans, LA 70112, USA. E-mail: whellst@tulane.edu

How to cite this article: Koller CR, Soubra A, Tannenbaum J, Alzweri L, Hellstrom W. Methods for managing erectile function in cis- and trans-male patients after neophallus reconstruction. Plast Aesthet Res 2021;8:8. DOI:10.20517/2347-9264.2020.137

Received: 19 Jun 2020 First Decision: 24 Aug 2020 Revised: 18 Dec 2020 Accepted: 12 Jan 2021 Published: 28 Jan 2021

Academic Editors: Marlon E. Buncamper, Raúl González-García Copy Editor: Xi-Jun Chen Production Editor: Yue-Yue Zhang

\begin{abstract}
Understanding the methods and rationale for managing erectile function in cis- and trans-male patients after neophallus reconstruction is of clinical value to the practicing urologists who encounter such patients. We describe a brief overview of the urologist's role in the management of sexual function. This communication focuses on pre- and post- construction of a neophallus, considerations for surgical techniques that are largely dependent on whether the patient is cis- or transgender, the traditional method of placing of inflatable penile prosthesis in a neophallus, and in conjunction with the management of complications post implantation. This manuscript is both a review of the current literature in the field, as well as an overview of experience gained from managing a cohort of patients over the years. Additionally, we discuss novel advances that aim to decrease the risk of complications, including distal erosion of the cylinders of the penile prostheses and the proximal dislodgement of cylinders in these unique patients.
\end{abstract}

Keywords: Neophallus reconstruction, erectile function, urology, cis, trans, urologic reconstruction, andrology, inflatable penile prosthesis

\section{INTRODUCTION}

Managing a patient's erectile function after reconstructive neophallus surgery can be a challenge to the urologist. Early reconstructive neophallus surgery was first documented in 1936, when the Russian surgeon,

cc) (i) (C) The Author(s) 2021. Open Access This article is licensed under a Creative Commons Attribution 4.0 International License (https://creativecommons.org/licenses/by/4.0/), which permits unrestricted use, sharing, adaptation, distribution and reproduction in any medium or format, for any purpose, even commercially, as long as you give appropriate credit to the original author(s) and the source, provide a link to the Creative Commons license, and indicate if changes were made.

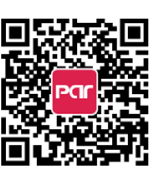


Borogaz, used an abdominal flap and autologous rib cartilage to create a phallus on a cis-male ${ }^{[1]}$. Efforts continued to progress, and, in 1946, Sir Harold Gillies performed the first successful gender affirmation neophallus construction ${ }^{[2]}$. The nature of these reconstructive surgeries does not provide for native erectile tissues; hence, the use of a penile prosthesis (PP) is imperative to produce an erection for penetrative sexual function.

Using a PP to treat erectile dysfunction has been attempted for more than 500 years, but, with the discovery of silicone in 1973, there has been a rapid rate of development due to its biocompatibility and long lifespan ${ }^{[3]}$. The introduction of the inflatable penile prothesis (IPP) allows a patient to proceed from flaccid to erect state and vice versa, which mimics a physiologic erection and provides for greater satisfaction ${ }^{[4]}$. Notable advances in penile prosthetics include true nylon tubing to decrease kinking, "Jonas" ${ }^{\text {[5] }}$ silicone prosthesis with silver wires to create a truly malleable device, one-way lock-out valves to prevent auto inflation, and antibiotic device coatings to help reduce infection rates. These technological advancements have decreased complication rates with IPP insertion and made it possible for men with erectile dysfunction and, more recently, cis- and transgender patients to regain erectile function ${ }^{[6]}$.

Due to the increasing number of patients undergoing neophallus reconstruction, urologists are playing a more important role in their long-term medical and surgical care. It is recognized that both cis and trans patients are prone to postoperative complications and familiarity by urologists with neophalluses optimizes outcomes. In addition, because urologists are most commonly the surgeons performing the insertion of the PP, having an intimate understanding of anatomy as it relates to prosthetic insertion and repair is critical. These patients, as we discuss, require specialized care; however, they are generally satisfied with the results similar to that of men undergoing routine implant surgery. In a small questionnaire-based study, the overall satisfaction of these patients measurably improved in terms of orgasmic function, intercourse satisfaction, and overall sexual satisfaction after insertion of $\mathrm{PP}^{[6]}$.

In this review, we focus on the preoperative evaluation of patients with neophalluses desiring a penile implant, review different techniques published in the literature, describe a novel way of anchoring the implant proximally to the pelvic rami, and summarize published outcomes.

\section{PREOPERATIVE EVALUATION}

There are several preoperative considerations to address when planning the placement of PP in patients with a neophallus. Ideally, the urologist managing the patient's sexual function participated in the initial reconstruction of the neophallus; if this is not the case, obtaining the operative reports and conversing with the surgeon who performed the reconstruction is invaluable. Understanding the neurovascular anatomy of the neophallus is important, especially when planning the placement of the IPP reservoir. A comprehensive history and physical exam focus on previous surgical reconstruction, the neourethra, and the shape and size of the neophallus. In addition to proper patient counseling, understanding the patients' goals and setting realistic expectations are integral parts of a successful evaluation. Generally, cross-sectional imaging with or without $3 \mathrm{D}$ reconstruction can be valuable in surgical planning [Figure 1].

It is not uncommon for many of these patients to already have postoperative imaging studies after their initial reconstruction. These images are usually obtained to assess for complications, most commonly being urethrocutaneous fistulas, which occur in between $15 \%$ and $70 \%$ of cases ${ }^{[7]}$. This is important in the preoperative period, as the risk of prosthetic infection without fistulas ranges $8 \%-20 \%{ }^{[8]}$. Fistulas occur most commonly at the anastomosis between the native and neourethra, but they can be found at any point along the urethra, and, should a fistula be present at time of IPP insertion, the risk of device infection and complications from urine extravasation dramatically increases. 


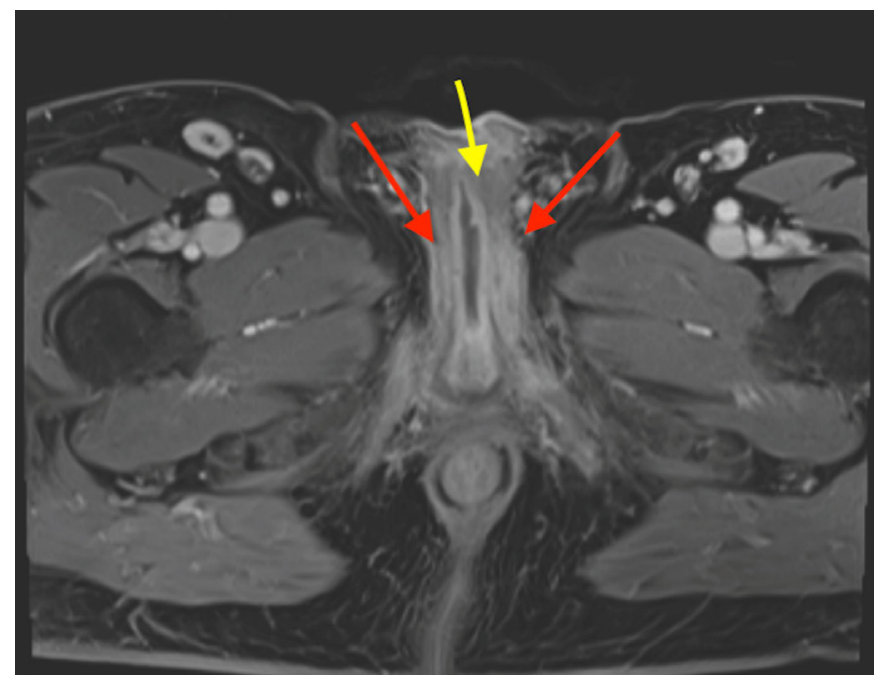

Figure 1. Preoperative magnetic resonance imaging (MRI) pelvis in a 50-year-old male who had a severely infected IPP and underwent a penectomy at an outside facility. Patient was referred for neophallus reconstruction with the goal of future IPP placement. MRI allows evaluating important landmarks, such as location of proximal urethral stump (yellow/middle arrow) and the position and length of the remaining corporal bodies (red/outside arrows). IPP: Inflatable penile prothesis.

Other urinary complications include sinus tracts, stones, pseudodiverticula, and urethral stricture at rates varying $10 \%-64 \%^{[9]}$, as reported in a large review by Leriche et al ${ }^{[10]}$ in 2019 . An antegrade voiding cystourethrogram that covers the entire length of urethra should be performed if there is any suspicion of urinary problems prior to planning the insertion of a PP. In-office flexible cystoscopy can also complement evaluation of the urethra and bladder in patients with other urinary complaints. Alternatively, one can perform a retrograde peri-urethrogram alongside an existing Foley catheter in patients still in the early recovery period ${ }^{[7]}$.

In patients without prior imaging, a preoperative magnetic resonance imaging scan with contrast aids in mapping out both native and reconstructed anatomy ${ }^{[11]}$. It is particularly useful in cis-male patients who have lost their native penis to trauma, infection, or malignancy. The evaluation of the remnant native proximal corpora will aid in the intraoperative decision-making process when considering implanting a PP proximally and for the creation of the urethral anastomosis to the neourethra in the reconstructed neophallus. In patients who had undergone gender affirmation surgery, imaging will help identify potential areas of concern from previous pelvic surgery such as hysterectomy, salpingo-oophorectomy, or vaginectomy. Finally, abdominal and pelvic imaging can aid in the preoperative planning of reservoir placement and ensure there is adequate space should a three-piece IPP be planned.

Unique challenges of placing implants in a neophallus include the lack of native penile tissue, specifically tunica albuginea, as well as natural ligamentous anchoring points to symphysis pubis and pubic rami; the decreased sensation of the neophallus that could protect from erosion; and the presence of neurovascular bundle that is no longer in its usual anatomic location. The timing of IPP placement is another critical point to consider. Insertion of a device is typically delayed or staged after initial reconstruction, and experts in the field have used six months after the last phalloplasty or urethral procedure as a reasonable time interval, wherein adequate healing and restoration of sensation is achieved.

\section{SURGICAL TECHNIQUE}

Similar to the reconstruction of a neophallus, different techniques and devices have been developed for implantation, with no clear evidence for superiority of one over the other ${ }^{[12]}$. The types of penile implants 


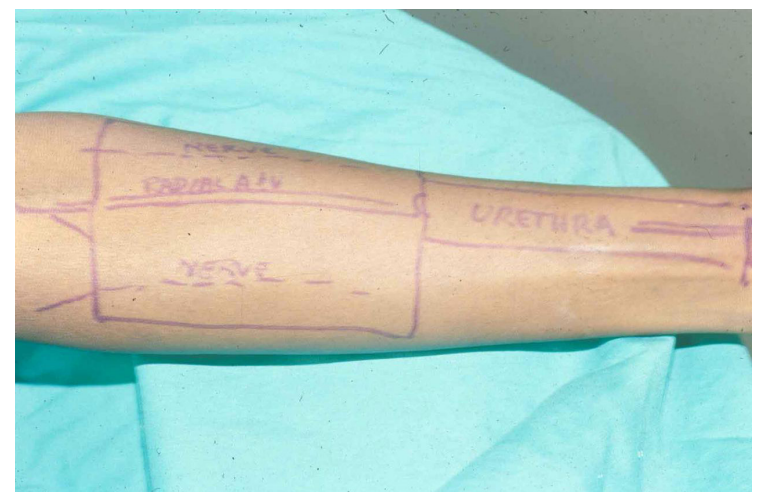

Figure 2. Preoperative skin drawings of radical-forearm free flap with neourethra, neoglans, and radial artery illustrated as mapping of surgical planning.

currently being used are the malleable non-inflatable rod, two-piece IPP (Boston Scientific, Malborough, MA, USA), three-piece IPP (Boston Scientific, Malborough, MA, USA and Coloplast, MN, USA), and three-piece ZSI 475 FtM implant (Zephyr Surgical Implants, Geneva, Switzerland). While the malleable implant is less complex and less costly than its IPP counterpart, its constant rigidity makes it difficult to conceal, and there is always the potential risk for distal erosion secondary to pressure necrosis of the flap. Hence, the most common type of implant used is the three-piece IPP (75\% of implants) ${ }^{[13]}$. Although a three-piece IPP comes with two cylinders, many are using a single cylinder, mainly due to the limitation of the neophallus girth and the absence the native tunica that exists.

The only two-piece IPP used in the USA is the Ambicor prosthesis (Boston Scientific, Malborough, MA, USA). The two-piece IPP offers an advantage in those with decreased manual dexterity due to its easier activation and deactivation mechanism, which also circumvents blindly placing a reservoir in potentially scarred regions and interfering with incoming blood supply to the free flap. Other models such as the ZSI 775 FtM implant (Zephyr Surgical Implants, Geneva, Switzerland) have a realistically shaped hard glans, a testicle-shaped pump, and a large surface area made of stainless steel for pubic bone fixation. Of note, the ZSI 775 FtM is not Food and Drug Administration approved for use in the USA; however, there are institutions in Europe that have reported success with placement of this model.

Our institutional experience has been with a two- or three-piece IPP placement in neophalluses constructed from radial forearm free flaps [Figure 2]. We routinely use a Foley catheter to help identify the neourethra, and we use a penoscrotal approach in both cis and trans patients. If a patient has native proximal corpora, these are opened sharply, stay stitches are placed, and the proximal corpora are subsequently dilated in the standard fashion. For the trans patient, this part of the procedure is similar; however, we carefully dilate proximally using Hegar dilators with the Foley catheter as a guide and boundary that identifies roughly the center of the neophallus. Distal dilation of the neophallus is also done carefully, as there is no distal corporal body to prevent the risk of perforation. When using a three-piece IPP, this is placed in the standard peno-scrotal fashion. This procedure is easier in a cis-male patient, as the proximal cylinder can be secured in the dilated proximal corpora. When performing surgery on trans patients or cisgender patients with neophallus, the use of intraoperative penile duplex Doppler ultrasound is helpful to locate, mark, and preserve the neurovascular bundle. Keith needles are placed through the mid-neoglans, and the device is inserted into the neophallus. We place the reservoir in the space of Retzius, if possible, on the contralateral side of the feeding blood supply to the flap; if this is not possible, submuscular placement of the reservoir is appropriate. The device is then connected and cycled to ensure it is functioning properly. Placing the pump into the neoscrotum can be a challenge in the final step. This should be done by carefully tunneling the pump into the posterior region of the scrotum and carefully suturing the pump, if needed, to secure it 
from riding upward. Oftentimes, if a three-piece device is placed, the neoscrotum will accommodate the pump; however, should there not be sufficient room, the pump can be placed ectopically or the choice of a two-piece prosthesis may be made. Patients are routinely discharged the following morning after receiving intravenous antibiotics and subsequently follow up in the clinic 1-2 weeks later for a routine postoperative evaluation. Device inflation/deflation, as routine, commences 6-8 weeks after surgery.

Some modifications to this standard placement process are the use of additional implant materials to mimic tunica and the placement of the IPP at time of initial neophallus construction. In trans patients, we, as well as many other centers, have used GORE-TEX ${ }^{\circledR}$ neotunica anchored to each of the ishial rami with success. This anchoring technique, which has been described previously by others, allows for decreased risk of device migration by providing a physical compartment for the cylinders to be placed into ${ }^{[14]}$. This part of the operation is completed initially after dissecting into the neophallus in preparation for the placement of the cylinder(s).

Finally, a more aggressive modification that should only be attempted in rare cases, is the placement of an IPP at the time of neophallus construction. This is possible if the surgeons are using a "Cricket Bat Technique" flap, often described as a tube within a tube, which allows for the placement of the reservoir, cylinders, and pump all at once during the free flap attachment. This is a surgical option for patients and surgeons who decide this to be a reasonable choice, which is based on patient goals, expectations, and the patient's anatomy and medical history.

"Cricket Bat" neophalluses are created by using the radial artery as blood supply; the distal aspect of the flap is constructed into a tube over a Foley catheter ${ }^{[15]}$. The neourethra is created and then folded on the underside of the bat portion of the free flap. The neourethra can then be anastomosed to the native proximal urethral tissue. Lastly, the lateral portions of the flap are wrapped around either side of the neourethra with the Foley catheter in place. This technique allows for cylinders to be placed into the lateral components of the flap far enough away from the neourethra and blood supply. While, typically, IPP placement is delayed, this is an option that some urologists may consider based on all history and intraoperative findings. As shown in Figure 3, the cylinders of the IPP are placed into the proximal corpora of this cis-male patient and they will insert directly into the free-flap. The vascular and urethra anastomosis are subsequently completed, and the device can be activated after the patient heals from the reconstruction.

It should be noted that there are a variety of penile reconstructive options available to surgeons. The radial forearm flap is the most commonly described in the literature as the standard technique. When looking at retrospective outcome data from high volume centers such as the Belgian group at Ghent University Hospital, Monstrey et al. ${ }^{[16]}$ demonstrated that radial forearm flaps are reliable and have high levels of success, particularly with endpoint goals of patients being able to stand to void as well as achieve sexual satisfaction.

\section{ALTERNATIVE SURGICAL ANCHORING TECHNIQUES}

The proximal anchoring of an IPP into a neophallus can be challenging, especially in patients without native proximal corpora cavernosa. While we often use a tubularized GORE-TEX ${ }^{\circledR}$ sleeve and attach them to each ischial ramus, other techniques proposed by Cohen et al. ${ }^{[14]}$ have used a proximal bone anchor at the level of the pubic symphysis via corticotomy with good results, allowing for decreased risk of cylinder migration.

In collaboration with Boston Scientific, we developed a novel technique for placement of PP by enforcing proximal fixation using a modification of AdVance ${ }^{\mathrm{TM}}$ Male Slings (Boston Scientific, Marlborough, MA) ${ }^{[17]}$. This technique has been successfully performed in cadaveric models and we hypothesize it will become 

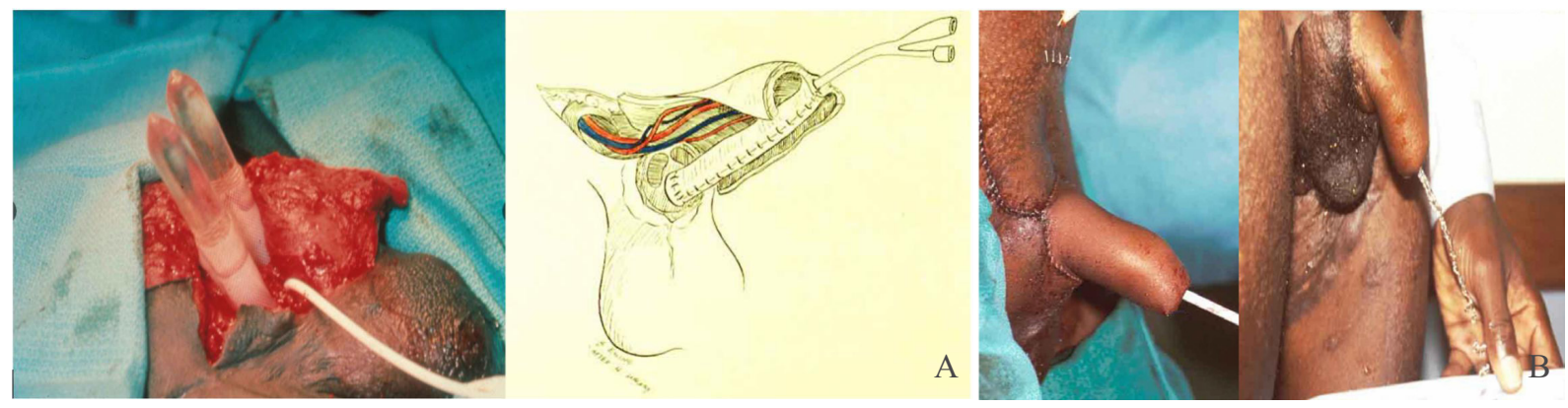

Figure 3. An intraoperative neophallus procedure with placement of IPP at time of construction on a cis male who lost native penis after tricorporal priapism. The patient required exchange blood transfusion secondary to sickle cell disease. A two-piece device was placed at time of surgery and the patient was able to activate after healing from Cricket Bat reconstruction eight weeks postop (A, Left); an artistic rendition of free flap demonstrating urethroplasty and re-anastomosis of vascular supply, pre-IPP insertion. Illustration by Betsy Ewing, Tulane University (A, Right); photo illustrating immediate postoperative outcome of IPP placed at time of neophallus construction (B, Left); postoperative image of patient voiding at three months with well-functioning IPP (B, Right). IPP: Inflatable penile prothesis.

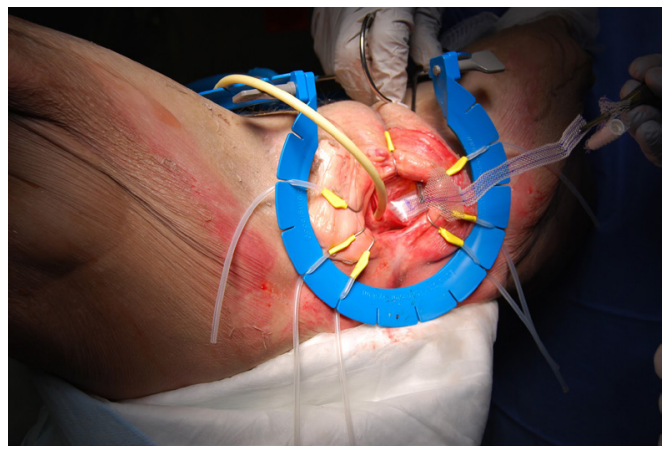

Figure 4. Male sling hammock: a holster of mesh attached to a rear tip extender (white/right arrow) is fashioned and secured to an AdVance Male Sling (green/left arrow) that is passed in a trans-obturator fashion. The holster is fixed to the pubic ramus by tightening the bilateral sling arms.

a viable technique for anchoring the proximal prosthetic cylinder, especially in trans patients. Using this technique, placement of the IPP can be performed from a perineal approach, which exposes the junction between inferior ramus of the ischium. Measurements of the neophallus are performed using standard techniques. A holster of mesh attached to a rear tip extender (RTE) is fashioned and secured to the AdVance $^{\mathrm{TM}}$ Male Sling that is passed in a trans-obturator fashion [Figure 4]. The holster is fixed to the pubic ramus by tightening the bilateral sling arms [Figure 4]. Finally, 2-0 PDS sutures are used to secure the holsters to the periosteum. The IPP is then placed in the standard fashion, now with an anchor that prevents the device from migrating proximally via suturing through the RTEs [Figure 5].

This novel approach of extra-corporal placement of an IPP and the use of male slings for proximal anchoring is relatively simple, does not require significant dissection, and does not necessitate placement of a neotunica, which can be technically more challenging. Once this technique's feasibility and safety are proven in patients with neophallus, it may offer better axial rigidity and stability of the device than current techniques, especially in transgender men, or in cis-male patients with severely damaged or fibrosed proximal corpora.

\section{OUTCOMES}

The current literature consists of a small number of retrospective series that assess outcomes of PP in neophalluses of cis- and transgender patients. To the best of our knowledge, there is only one systematic 


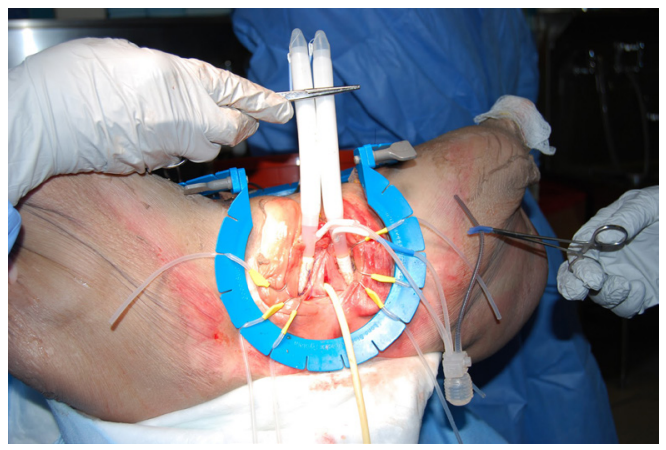

Figure 5. Placement of IPP by modification of AdVance Male Sling. Successful anchoring of IPP using male slings in a trans-obturator fashion. IPP: Inflatable penile prosthesis.

Table 1. Complication rates for patients who required additional surgical intervention after penile prosthesis insertion ${ }^{[12]}$

\begin{tabular}{ll}
\hline & Patients, \% ( $)$ \\
\hline Total complications & \\
Total complication rate & $36.2(287)$ \\
Total inflatable complication rate & $45.2(217)$ \\
Total non-inflatable complication rate & $41.5(27)$ \\
Specific complications & \\
Mechanical failure, dysfunction, or leak & $12.0(85)$ \\
Infection of device & $8.6(61)$ \\
Patient dissatisfaction & $6.8(48)$ \\
Inadequate fixation, migration, or mispositioning & $5.2(37)$ \\
Erosion & $3.4(24)$ \\
Other & $1.0(7)$ \\
\hline
\end{tabular}

review and meta-analysis pooling all these data ${ }^{[12]}$. Excluding non-English articles and those that have used transgender-specific prosthesis, the authors identified a total of 22 studies. The total number of patients receiving implants was 792 patients, $96.2 \%$ of whom were transgender and the mean follow up was three years. There was a significant variability in the reported outcomes in each of the studies, hence the pooled data for each outcome are derived from different subsets of articles. For instance, mean age at implantation was 36.7 years accounting for 422 patients, whereas interval to implantation between neophallus construction at IPP was 2.4 years based on data from 177 patients in eight articles. Overall, $83.6 \%$ of implants used were inflatable and $61 \%$ were single cylinder. Most patients (83.9\%) were able to achieve penetration $(n=230)$. The total complication rate (defined as any further surgical intervention) was $36.2 \%(n=287)$ with no apparent major difference between inflatable and noninflatable devices $(45.2 \% v s$. $41.5 \%$, respectively). Table 1 displays the rate of different complications calculated by the above-mentioned study $^{[12]}$.

Notably, patients in this review had a total device infection rate of $8.6 \%$; this can be contrasted against historical outcomes in patients with IPPs placed into native penile tissue. Carson et al ${ }^{[18]}$ presented highquality long-term device infection data at 7.7 years with a $1.1 \%-2.5 \%$ infection rates depending on type of device used.

In a review focusing on two-piece IPPs only, the overall complication rate of such implant was higher in transgender patients (35.6\%, as compared to $2 \%-11 \%$ in cisgender men). There were no mechanical failures at mean follow up of 11.85 months. The infection rate was reported to be $15.3 \%$. Of note, unlike the threepiece IPP, the Ambicor prosthesis is not coated with an antibiotic surface treatment ${ }^{[19]}$. 
As for the ZSI $475 \mathrm{FtM}$ prosthesis, the data from a series of 20 patients show that two patients experienced mechanical failure, one experienced implant infection, and one had cylinder mispositioning, for which all had revision procedures ${ }^{[20]}$.

These outcomes can be supported in another series published by the University College of London group, Falcone et al ${ }^{[21]}$ in 2017 , which illustrated overall revision rates of $43 \%$ with infections occurring in $8.5 \%$ of devices; patients, however, were overall very satisfied with the results at $88 \%$, with $77 \%$ of this cohort able to use their implants for sexual intercourse. They showed no preference or significant differences in outcomes based on device used. Hoebeke et al. ${ }^{[22]}$ published their experience of implanting different prostheses in 129 transgender men with a mean follow up of 56.5 months. At the end of the study, 58.9\% had their original implant in place and the rest underwent revision or explant for different reasons. The most common reason was device malposition or dysfunction, followed by infection and protrusion.

\section{CONCLUSION}

The management of erectile function, particularly that of PP insertion and follow-up of patients with neophalluses, is both challenging and rewarding for urologists who deal with this patient population. Care for this surgically complex patient demographic requires an intimate knowledge of anatomy, shared decision making and clearly set expectations between surgeon and patient, and meticulous attention to detail to help limit complications and maximize the utility of the prosthesis. Future studies need to evaluate the comparability of anchoring the IPP using our modified male sling as compared to the traditional anchoring method in transgender patients. Continued refinements of established techniques and recent innovative approaches will cumulatively result in improved outcomes of neophallus reconstruction and subsequent PP implantation.

\section{DECLARATIONS}

\section{Authors' contributions}

Made substantial contributions to conception and design of the study: Alzweri L, Hellstrom W

Performed data analysis and interpretation: Koller CR

Performed data acquisition, as well as provided administrative, technical, and material support:

Tannenbaum J

Drafted the original work: Koller CR, Soubra A

Substantially revised drafted work: Soubra A, Alzweri L, Hellstrom W

\section{Availability of data and materials}

Not applicable.

\section{Financial support and sponsorship}

None.

\section{Conflicts of interest}

Dr. Wayne Hellstrom is a consultant for Boston Scientific and Coloplast. All other authors declare that there are no conflicts of interest.

\section{Ethical approval and consent to participate}

Not applicable.

\section{Consent for publication}

Not applicable. 


\section{Copyright}

(c)The Author(s) 2021.

\section{REFERENCES}

1. Bogoraz NA. On complete plastic reconstruction of a penis sufficient for coitus. Sov Surg 1936;8:303-9.

2. Nair R, Sriprasad S. 1129 Sir Harold Gillies: pioneer of phalloplasty and the birth of uroplastic surgery. J Urol 2010;183:e437.

3. Lash H, Zimmerman DC, Loeffler RA. Silicone implantation: inlay method. Plast Reconstr Surg 1964;34:75-80.

4. Scott FB, Bradley WE, Timm GW. Management of erectile impotence. Use of implantable inflatable prosthesis. Urology 1973;2:80-2.

5. Jonas U, Jacobi GH. Silicone-silver penile prosthesis: description, operative approach and results. J Urol 1980;123:865-7.

6. Young EE, Friedlander D, Lue K, et al. Sexual function and quality of life before and after penile prosthesis implantation following radial forearm flap phalloplasty. Urology 2017;104:204-8.

7. Blaschke E, Bales GT, Thomas S. Postoperative imaging of phalloplasties and their complications. AJR Am J Roentgenol 2014;203:3238.

8. D'Arpa S, Claes K, Lumen N, Oieni S, Hoebeke P, Monstrey S. Urethral reconstruction in anterolateral thigh flap phalloplasty: a 93-case experience. Plast Reconstr Surg 2019;143:382e-92e.

9. Jun MS, Santucci RA. Urethral stricture after phalloplasty. Transl Androl Urol 2019;8:266-72.

10. Leriche A, Timsit MO, Morel-Journel N, Bouillot A, Dembele D, Ruffion A. Long-term outcome of forearm flee-flap phalloplasty in the treatment of transsexualism. BJU Int 2008;101:1297-300.

11. Koller C, Alzweri L, Tsambarlis P, Youssef A, Jansen D, Hellstrom W. 361 evolution of radial forearm free flap neophallus construction for future prosthetic intervention and decreased urinary complications in cis-male patients. J Sex Med 2020;17:S97-8.

12. Rooker SA, Vyas KS, DiFilippo EC, Nolan IT, Morrison SD, Santucci RA. The rise of the neophallus: a systematic review of penile prosthetic outcomes and complications in gender-affirming surgery. $J$ Sex Med 2019;16:661-72.

13. Kocjancic E, Iacovelli V. Penile prostheses. Clin Plast Surg 2018;45:407-14.

14. Cohen AJ, Bhanvadia RR, Pariser JJ, Hatcher DM, Gottlieb LJ, Bales GT. Novel technique for proximal bone anchoring of penile prosthesis after radial forearm free flap neophallus. Urology 2017;105:2-5.

15. Semple JL, Boyd JB, Farrow GA, Robinette MA. The "cricket bat" flap: a one-stage free forearm flap phalloplasty. Plast Reconstr Surg 1991;88:514-9.

16. Monstrey S, Hoebeke P, Selvaggi G, et al. Penile reconstruction: is the radial forearm flap really the standard technique? Plast Reconstr Surg 2009;124:510-8.

17. Alzweri L, Koller C, Yousif A, Peterson S, Hellstrom W. 017 novel technique for extra-corporal placement of penile prosthesis in cis and transgender male: the modified use of advance male sling for proximal anchoring. J Sex Med 2020;17:S8.

18. Carson CC 3rd, Mulcahy JJ, Harsch MR. Long-term infection outcomes after original antibiotic impregnated inflatable penile prosthesis implants: up to 7.7 years of followup. J Urol 2011;185:614-8.

19. Ko OS, Bennett NE Jr. Ambicor two-piece inflatable penile prosthesis: background and contemporary outcomes. Sex Med Rev 2018;6:319-27.

20. Neuville P, Morel-Journel N, Cabelguenne D, Ruffion A, Paparel P, Terrier JE. First outcomes of the ZSI 475 FtM, a specific prosthesis designed for phalloplasty. J Sex Med 2019;16:316-22.

21. Falcone M, Garaffa G, Gillo A, Dente D, Christopher AN, Ralph DJ. Outcomes of inflatable penile prosthesis insertion in 247 patients completing female to male gender reassignment surgery. BJU Int 2018;121:139-44.

22. Hoebeke PB, Decaestecker K, Beysens M, Opdenakker Y, Lumen N, Monstrey SM. Erectile implants in female-to-male transsexuals: our experience in 129 patients. Eur Urol 2010;57:334-40. 